\title{
INFLUÊNCIA DOS ADJUVANTES NA SECAGEM DA POLPA DE PITANGA EM LEITO DE JORRO
}

\author{
A. B. M. LIMA ${ }^{1}$, S. C. de M. DANTAS ${ }^{1}$, S. M. de P. JÚNIOR ${ }^{1}$, T. N. P. DANTAS ${ }^{1}$ e M. F. \\ D. de MEDEIROS ${ }^{1}$
}

${ }^{1}$ Universidade Federal do Rio Grande do Norte, Departamento de Engenharia Química E-mail para contato: mfatimadmedeiros@gmail.com

\begin{abstract}
RESUMO - Dentre os métodos alternativos de secagem de polpas de frutas, o secador de leito de jorro com partículas inertes tem se apresentado como uma alternativa eficiente. Contudo, limitações inerentes ao próprio processo de secagem, como o efeito da composição das frutas, impedem que este secador apresente um desempenho compatível quando comparado com outras técnicas. Analisou-se a secagem da polpa de pitanga testando-se diferentes formulações que incluíam misturas da polpa de pitanga com leite fluido, leite em pó, e uma combinação do leite fluido com a proteína do soro do leite. Com leite fluido e leite em pó os rendimentos foram de $17.9 \%$ em média. Com adição do leite fluido e $1 \%$ da proteína do soro do leite o rendimento alcançou $38 \%$ o que demonstra a influência da combinação desse adjuvante na secagem da polpa de pitanga. A ação combinada dos adjuvantes (proteína e leite) demonstra não só um maior rendimento como também a produção de pós mais secos e com menor atividade de água.
\end{abstract}

\section{INTRODUÇÃO}

Originária do Brasil, a pitangueira (Eugenia uniflora L.) cresce em regiões de clima tropical e subtropical e seu fruto, a pitanga, é valorizado pelo sabor, beleza e aspectos nutricionais. Devido a sua adaptabilidade às mais distintas condições de solo e clima, esta frutífera foi disseminada e é atualmente encontrada nas mais variadas regiões do globo. Rica em vitaminas (principalmente a vitamina A e C), cálcio, fósforo, antocianinas, flavonoides, carotenoides e antioxidante, a pitanga tem sido amplamente exportada para o mercado europeu, além de despertar o interesse das indústrias farmacêuticas (Silva, 2016). Embora a produção de pitanga não apresente grandes limitações, a elevada perecibilidade provoca a redução da qualidade da fruta, sendo muitas vezes desperdiçada. Dessa forma, métodos de secagem da pitanga devem ser pesquisados com o intuito de reduzir suas perdas.

$\mathrm{Na}$ secagem de polpas e extratos de frutas são utilizados processos como liofilização, secagem por atomização (spray dryer), em camada de espuma (foam mat), em leito fluidizado e em leito de jorro com partículas inertes. Este último tem sido muito estudado ao longo dos últimos anos, apresentando bom desempenho na produção polpas de frutas em pó com baixo teor de umidade e preservação das vitaminas e compostos nutricionais. Por sua dinâmica e capacidade de mistura, o leito de jorro é contemplado por elevados coeficientes de transferência de calor e massa e distribuição de temperatura de secagem uniforme (Araújo et 
al., 2015). Todavia, muitas vezes a composição das frutas, rica em açucares redutores, inviabiliza o processo de secagem de suas polpas em leito de jorro, em função da formação de pós pegajosos que geram acúmulo de material no leito de partículas inerte, comprometendo a dinâmica do secador e provocando colapso do jorro.

Esses problemas têm sido minimizados pela adição de adjuvantes de secagem como o leite (Braga et al., 2013; Machado, 2014), proteínas do soro de leite (Fang e Bandhari, 2012; Bhusari et al., 2014) e misturas com elevado teor de amido (Ordoñez e Herrera, 2014). Este trabalho tem por objetivo avaliar a interferência que adjuvantes como o leite e proteína do soro do leite podem exercer nas características físico-químicas da polpa da pitanga e no rendimento do processo de secagem no leito de jorro.

\section{METODOLOGIA EXPERIMENTAL}

A polpa de pitanga empregada foi adquirida congelada no mercado local e mantida nesta condição até sua utilização. O preparo das misturas envolvia a pesagem dos componentes (polpa in natura e adjuvantes) em uma balança analítica (ED330, MARTE, BRASIL), e homogeneização através da agitação constante em liquidificador doméstico durante 1 minuto. Os adjuvantes utilizados foram: leite de vaca fluido, proteína do soro do leite, leite de vaca em pó. As formulações utilizadas podem ser visualizadas na Tabela 1.

Tabela 1 - Formulação das misturas

\begin{tabular}{cccccc}
\hline Formulações & Legenda & $\begin{array}{c}\text { Polpa } \\
(\%)\end{array}$ & $\begin{array}{c}\text { Leite } \\
\text { Fluido }(\%)\end{array}$ & $\begin{array}{c}\text { Leite em } \\
\text { pó } * *(\%)\end{array}$ & $\begin{array}{c}\text { Proteína do } \\
\text { leite* }(\%)\end{array}$ \\
\hline $\begin{array}{c}\text { Pitanga/Leite } \\
\text { Fluido }\end{array}$ & $\mathrm{PL}_{\mathrm{f}}$ & 72 & 28 & - & - \\
$\begin{array}{c}\text { Pitanga/Leite } \\
\text { fluido/Proteína } \\
\text { do soro do leite } \\
\text { Pitanga/Leite em } \\
\text { pó }\end{array}$ & $\mathrm{PL}_{\mathrm{f}} \mathrm{W}$ & 70 & 29 & - & 1 \\
\hline
\end{tabular}

\subsection{Determinações físico-químicas}

Foram realizadas análises para determinação da densidade, sólidos solúveis, sólidos totais, umidade e $\mathrm{pH}$ da polpa de pitanga e das misturas polpa-adjuvantes, bem como da umidade e atividade de água dos pós. Todas as análises foram realizadas em triplicata.

Os sólidos totais (ST) da polpa in natura e das misturas, assim como a umidade dos pós, foram determinados em estufa de circulação de ar a 70 ${ }^{\circ} \mathrm{C}$ (TECNAL TE-394/I, Brasil) até peso constante. Os sólidos solúveis (SS) foram medidos em refratômetro de bancada 
(ATAGO, SMART-1) e expressos em ${ }^{\circ}$ BRIX, e o $\mathrm{pH}$ medido em potenciômetro de bancada. As densidades foram medidas em picnômetros previamente tarados e expressas em $\mathrm{g} / \mathrm{mL}$ (AOAC, 2012).

\subsection{Ensaios de secagem}

O equipamento empregado, construído em aço inoxidável, é constituído por uma coluna cilíndrica (18 cm de diâmetro e $72 \mathrm{~cm}$ de altura) acoplada a uma base cônica (ângulo incluso $60^{\circ}, 13 \mathrm{~cm}$ de altura) com um orifício central ( $3 \mathrm{~cm}$ de diâmetro), por onde é injetado uma corrente de gás. Acoplado a coluna, tem-se um ciclone (10 $\mathrm{cm}$ de diâmetro da coluna) que promove a separação entre o pó e o ar. O pó é coletado na parte inferior do ciclone por sacos plásticos de $300 \mathrm{~mL}$. A formação do jorro se dá pela passagem desse gás através das partículas, de tal forma que a circulação das partículas é iniciada quando a vazão do gás é suficiente para provocar o seu movimento ascendente. Na Figura 1, observa-se o esquema descrito do leito de jorro.

Figura 1- Esquema do leito de jorro

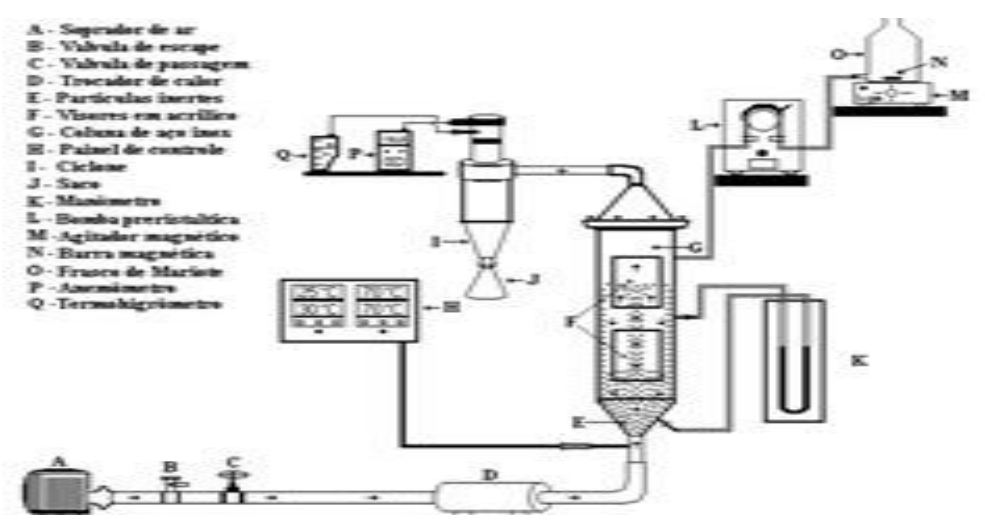

Como material inerte, utilizou-se uma carga de partículas de $2500 \mathrm{~g}$ de polietileno de alta densidade. Estas apresentam diâmetro médio igual a 3,2 $\pm 0,05 \mathrm{~mm}$ com densidade real de $0,875 \pm 0,468 \mathrm{~g} / \mathrm{cm}^{3}$. Em todos os ensaios, foram estabelecidas condições fixas de secagem. A vazão de alimentação das misturas foi aproximadamente $6,4 \mathrm{~mL} / \mathrm{min}$, gotejante e intermitente (6 minutos alimentando e 8 minutos parado). A velocidade do ar na coluna e a temperatura de entrada foram fixadas em $13 \mathrm{~m} / \mathrm{s}$ e $70^{\circ} \mathrm{C}$, respectivamente. $\mathrm{O}$ rendimento $\left(\eta_{\text {rend }}\right)$ foi calculado conforme a Equação 1.

$\eta_{\text {rend }}=\frac{\left(1-X_{p o ́}\right) \cdot \sum m_{p o ́} i}{\left(1-X_{\text {susp }}\right) \cdot \sum m_{\text {susp }} i} \cdot 100$

\section{RESULTADOS E DISCUSSÕES}

$\mathrm{Na}$ Tabela 2, são encontradas as características físico-químicas obtidas experimentalmente, acompanhada da média e do desvio padrão amostral. Aos dados obtidos, 
foi aplicado o teste de Tukey (HSD) e verificado, a 5\% de significância, a diferença estatística entre as amostras estudadas.

Tabela 2 - Característica físico-química das misturas.

\begin{tabular}{ccccc}
\hline Amostras & Densidade $(\mathbf{g} / \mathbf{m l})$ & SS $\left({ }^{\circ} \mathbf{B R I X}\right)$ & $\mathbf{p H}$ & ST (\%) \\
\hline Pitanga & $1,01 \pm 0,03^{\mathrm{a}}$ & $3,82 \pm 0,01^{\mathrm{a}}$ & $3,00 \pm 0,04^{\mathrm{a}}$ & $4,33 \pm 0,24^{\mathrm{a}}$ \\
PLf & $1,02 \pm 0,02^{\mathrm{a}}$ & $6,04 \pm 0,05^{\mathrm{b}}$ & $3,75 \pm 0,01^{\mathrm{b}}$ & $7,04 \pm 1,65^{\mathrm{b}}$ \\
PL $_{\mathbf{F}} \mathbf{W}$ & $1,02 \pm 0,03^{\mathrm{a}}$ & $6,46 \pm 0,06^{\mathrm{c}}$ & $3,75 \pm 0,01^{\mathrm{b}}$ & $7,61 \pm 0,35^{\mathrm{b}}$ \\
PL $_{\mathbf{p}}$ & $1,02 \pm 0,01^{\mathrm{a}}$ & $6,36 \pm 0,15^{\mathrm{c}}$ & $3,46 \pm 0,03^{\mathrm{b}}$ & $9,01 \pm 0,88^{\mathrm{c}}$
\end{tabular}

Letras diferentes indicam diferenças significativas pelo teste Tukey, ao nível de significância de $5 \%$.

Estatisticamente, as densidades das misturas analisadas em relação à polpa in natura não apresentaram diferenças significativas. Todas as misturas apresentaram teores de sólidos solúveis superiores ao da polpa. Entre si, as misturas com adição do leite fluido e em pó diferem significativamente, resultado do maior percentual de leite existente neste último. Entretanto, as misturas com adição de leite fluido e proteína do leito não diferem estatisticamente da mistura com adição apenas do leite em pó. $\mathrm{O}$ aumento no teor de sólidos solúveis decorre do elevado teor de componentes solúveis presentes no leite, especialmente na proteína do soro do leite.

Quanto ao $\mathrm{pH}$, percebe-se que as misturas apresentam valores mais elevados e significativamente diferentes da polpa em decorrência do $\mathrm{pH}$ básico do leite. Observa-se ainda, o aumento significativo do teor de sólidos totais nas misturas em relação à polpa in natura, visto que a adição do leite, fluido ou na forma de pó, e da proteína do soro de leite, ambos com teor de sólidos totais bem mais elevados do que a polpa, contribui para obtenção de mais sólidos. Com adição do leite em pó, o teor de sólidos totais diferiu significativamente dos valores observados para as misturas com adição do leite fluido.

Os dados da produção acumulada de pó para cada experimento, em função do tempo, encontram-se representados na Figura 2. Os dados da produção nos ensaios com adição do leite fluido ou em pó, praticamente se sobrepõem, o que demonstra que a adição da proteína do soro do leite provocou importante aumento na produção. Em todos os experimentos, é possível visualizar dois períodos distintos para a produção de pó que tende a aumentar no segundo período. Aos dados da massa acumulada em função do tempo, foi ajustado o modelo linear representado pelas retas exibidas na Figura 2, cujas inclinações representam a taxa de produção de pó em cada período.

Na Tabela 3, são exibidas as taxas de produção calculadas e respectivos coeficientes de correlação. O modelo linear aplicado pode ser considerado satisfatório para representar os dados experimentais, posto que os coeficientes de correlação são superiores a $94 \%$. 
Tabela 3 - Taxas de produção

\begin{tabular}{ccccc}
\hline Amostra & $\begin{array}{c}\text { Taxa1 } \\
(\mathbf{g} / \mathbf{m i n})\end{array}$ & $\begin{array}{c}\text { Taxa2 } \\
(\mathbf{g} / \mathbf{m i n})\end{array}$ & $\mathbf{R}^{\mathbf{2}} \mathbf{( 1 )}$ & $\mathbf{R}^{\mathbf{2}} \mathbf{( 2 )}$ \\
\hline $\mathbf{P L}_{\mathbf{f}}$ & 0,0213 & 0,0598 & 0,94 & 0,95 \\
$\mathbf{P L}_{\mathbf{p}}$ & 0,024 & 0,0567 & 0,97 & 0,98 \\
$\mathbf{P L}_{\mathbf{f}} \mathbf{W}$ & 0,0372 & 0,0972 & 0,95 & 0,98 \\
\hline
\end{tabular}

Figura 2 - Massa produzida em função do tempo

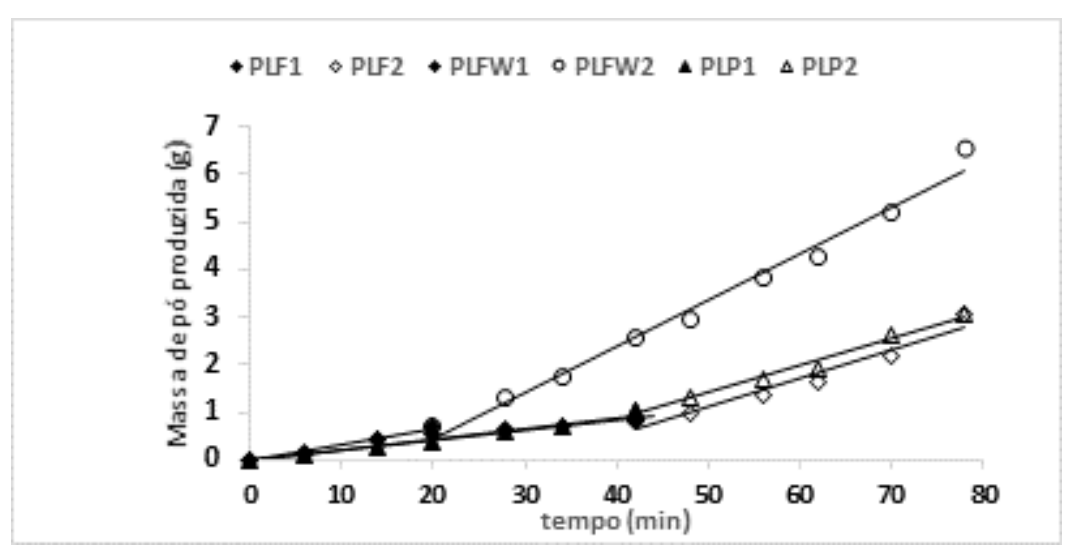

$\mathrm{Na}$ Tabela 4, são apresentados os resultados dos ensaios de secagem relativos à razão massa alimentada/massa produzida, rendimento, umidade e atividade de água dos pós obtidos. A secagem de polpa da pitanga pura foi impedida pelo colapso do jorro. Conforme se observa a adição do leite, na forma fluida ou em pó, contribuiu para viabilizar a secagem, todavia com uma baixa produção de pó. Observa-se que o maior rendimento $(38,2 \%)$ foi alcançado na secagem da polpa com adição de leite fluido e proteína do leite. Nos demais ensaios, não se observa diferença importante entre os rendimentos, 17,9\% em média.

Tabela 4 - Rendimento da produção e características dos pós obtidos.

\begin{tabular}{ccccc}
\hline Amostras & $\begin{array}{c}\text { Massa } \\
\text { Alimentada/Produzida } \\
(\mathbf{g} / \mathbf{g})\end{array}$ & $\begin{array}{c}\text { Rendimento } \\
(\boldsymbol{\%})\end{array}$ & $\begin{array}{c}\text { Umidade } \\
(\boldsymbol{\%})\end{array}$ & $\begin{array}{c}\text { Atividade } \\
\text { de água }\end{array}$ \\
\hline $\mathbf{P L}_{\mathbf{F}}$ & $182,1 / 3,05$ & 16,73 & 5,01 & 0,330 \\
$\mathbf{P L}_{\mathbf{F}} \mathbf{W}$ & $176,2 / 6,58$ & 38,02 & 4,34 & 0,301 \\
$\mathbf{P L p}$ & $201,3 / 4,55$ & 19,12 & 6 & 0,406 \\
\hline
\end{tabular}

Na Tabela 4, também se verifica que os valores de umidade e atividade de água dos pós apresentam valores próximos entre si, o que leva a se avaliar que não houve influência das diferentes formulações nas características dos pós. Todos os pós apresentaram atividade de 
água dentro da faixa estabelecida para alimentos secos na forma de pós, estáveis do ponto de vista microbiológico com atividade de água inferior a 0,4 .

\section{CONCLUSÕES}

A adição do leite associada ou não a proteína do soro do leite interferiram significativamente nas características físico-químicas das misturas. Os pós obtidos apresentaram umidade e atividade de água adequadas para conservação e armazenamento. Em todos os experimentos, foram observados períodos com distintas taxas de produção. Mediante avaliação dos dados apresentados e discutidos, conclui-se que a adição do leite fluido ou leite em pó como adjuvante, apresentaram rendimento semelhante a 17,9\% em média, porém com a adição de $1 \%$ da proteína do soro do leite o rendimento praticamente duplicou. Este resultado demonstra a importância da combinação leite / proteína do soro de leite na secagem da pitanga.

\section{REFERÊNCIAS}

A.O.A.C. 2012. Official Methods of the Analysis of AOAC. International 19th Edition, Published by AOAC International. Maryland 20877-2417, USA.

ARAúJO, A. D. A., COElHO, R. M. D.,. FOnTES, C. P. M. L, SilVA, A. R. A., COSTA, J. M. C. da RODRIGUES, S. Production and spouted bed drying of acerola juice contaming oligosaccharides. Food and Bioproducts Processing, v.94 p. 565-571, 2015.

BHUSARI, S. N.; MUZAFFAR, K.; PRADYUMAN, K. Effect of carrier agents on physical and microstructural properties of spray dried tamarind pulp powder. Powder Technology, v. 266, p. 354-364, 2014.

BRAGA, M. B.; ROCHA, S.C.S. Drying of milk-blackberry pulp mixture in spouted bed. Canadian Journal of Chemical Engineering, v. 91, p. 1780-1792, 2013.

FANG, Z.; BHANDARI, B. Comparing the efficiency of protein and maltodextrin on spray drying of bayberry juice. Food Research International, v. 48, p. 478-483, 2012.

MACHADO, I. P. Avaliação térmica e desempenho do processo de secagem de misturas de graviola e leite em secador de leito de jorro. 91f Dissertação. Pós-graduação em Engenharia química. Universidade Federal do rio grande do Norte. 2014.

ORDOÑEZ, M.; HERRERA, A. Morphologic and stability cassava starch matrices for encapsulating limonene by spray drying. Powder Technology, v. 253, p. 89-97, 2014.

SILVA, S. de M. Pitanga, Revista Brasileira de Fruiticultura. V. 28, n.1, p. 1-159. 2016. 